\title{
article
}

\section{The 'Scottish approach' to policy and policymaking: what issues are territorial and what are universal?}

\author{
Paul Cairney, p.a.cairney@stir.ac.uk, University of Stirling, UK \\ Siabhainn Russell, siabhainnrussell@abdn.ac.uk, University of Aberdeen, UK \\ Emily St Denny, emily.stdenny@stir.ac.uk, University of Stirling, UK
}

The 'Scottish approach' refers to its distinctive way to make and implement policy. Its reputation suggests that it is relatively comfortable with local discretion and variations in policy outcomes. Yet, policymakers are subject to 'universal' processes - limited knowledge, attention and coordinative capacity, and high levels of ambiguity, discretion and complexity in policy processes - which already undermine central control and produce variation. If policy is a mix of deliberate and unintended outcomes, a focus on policy styles may exaggerate a government's ability to do things differently. We demonstrate these issues in two 'cross cutting' policies: 'prevention' and 'transition'.

key words devolution $\cdot$ complexity $\cdot$ prevention $\cdot$ transition

To cite this article: Cairney, P, Russell, S, St Denny, E, (2016) The 'Scottish approach' to policy and policymaking: what issues are territorial and what are universal?, Policy \& Politics, 44, 3,

333-50, DOI: 10.1332/030557315X14353331264538

\section{Introduction: territorial and universal policy issues}

The 'Scottish approach' refers to the Scottish Government's reputation for pursuing a consultative and cooperative style when it makes and implements policy in devolved areas (including health, education, local government and justice). It works with voluntary groups, unions, professional bodies, the private sector and local and health authorities to gather information and foster support for its policy aims. This approach extends to policy delivery, with the Scottish Government willing to produce a broad national strategy and series of priorities - underpinned by the 'National Performance Framework' - and trust bodies such as local authorities to meet its aims. In turn, local authorities work with a wide range of bodies in the public, voluntary and private sector - in 'Community Planning Partnerships' - to produce shared aims relevant to their local areas. 'Single Outcome Agreements' mark a symbolic shift away from 'topdown' implementation, in which local authorities and other bodies are punished if 
they do not meet short-term targets, towards the production of longer-term shared aims and cooperation.

The specific term 'Scottish approach' has been used only recently by the Scottish Government to describe and evaluate a particular model of policymaking (Scottish Government and ESRC, 2013). However, other descriptions, such as the academic term 'Scottish policy style' (Keating, 2005; Cairney, 2008) have captured the potentially distinctive ways in which the Scottish Government makes and implements policy. Note that 'distinctive' usually refers to comparisons with the UK government, which can become a convenient target. One consequence of the comparison between Scottish and British policy styles is that it may portray the Scottish Government in a favourable light, at the expense of a critical analysis of the problems it faces and the ways in which it addresses them.Yet the concepts we use to analyse how governments deal with policymaking complexity are as important as their reputations.

We argue that, while there is an important territorial dimension to policy and policymaking, it should be viewed in the context of 'universal' issues that all governments face when they have limited powers to address a series of important, value-laden, trade-offs. The first is the trade-off between national and local policymaking, when governments seek to balance national standards and policy uniformity against local discretion. ${ }^{1}$ The second is the challenge of 'cross-cutting' policy areas which demonstrate the complexity of policymaking, and prompt us to examine the extent to which governments can choose to adopt a distinctive policymaking 'style'.

At the heart of this discussion are concepts which appear to be innocuous, and are used routinely by governments and commentators, but which are infused with normative meaning. Terms such as 'joined-up' government and 'coherent' policy promote the idea of centralisation and harmonisation, not undermined by governmental silos, and/or an ability to produce something that can be described meaningfully as a 'national' policy despite local discretion (Jordan and Halpin, 2006). At a national level, these concepts compete with the idea of pragmatic policymaking, based on the assumption that policymaking cannot be fully centralised, no policy can be truly 'holistic', and that there are practical benefits to the encouragement of policies driven primarily by specialists in each area (Cairney and Geyer, 2015). At a central-local level, governments may encourage 'bottom up' policy development. A degree of variation may be built into the design of policy, or otherwise encouraged, as a sign of local policymaking legitimacy and/or a desire to encourage community or service user participation in the design and delivery of services. In many 'cross-cutting' policy areas, these national and local issues may be faced simultaneously. Organisational issues intersect with issues of ambiguity, in which policymakers struggle to decide who is best placed to solve an ill-defined policy problem.

The language we use to describe policy coherence suggests that, in practice, it is impossible to separate normative evaluations from empirical descriptions. For example, we may describe 'fragmentation' or 'flexibility', or decide between negative terms such as 'postcode lottery' and more positive notions of 'community-led' policies or individualised services 'co-produced' by service users and other important stakeholders. Even the term 'devolution' assumes that central governments should decide which powers to retain and which to delegate to local bodies (McAteer, 2014).Analytically, when we focus primarily on the central-local dimension, the empirical emphasis is on the extent to which we can identify variation and similarity in the delivery of public 


\section{The 'Scottish approach' to policy and policymaking}

policies, while the normative focus is on how satisfied actors may be with potential and actual variation in outcomes. For example, we may reflect on the possibility that people with the same demands for, or needs of, services would receive a different service in different local areas - and consider how people weigh up the trade-off between the pursuit of national uniformity and local legitimacy.

The problem, however, extends far beyond the link between empirical studies and normative questions. It is complicated by a policy process that is too complex to manage, and problems that are too vaguely defined to be solved. Whenever policy problems span multiple departments, and multiple levels of government, and contain many actors, it is difficult to separate this normative focus on legitimate variation in policy outcomes from an empirical focus on the messy policy processes which produce unintended outcomes. The phrase 'complex government' sums up the argument that governments do not control policymaking systems (Cairney, 2015). A government cannot claim full credit for a degree of coherent policymaking, and nor should it take full responsibility for 'fragmented' public services and uneven outcomes. We have identified the theoretical possibility that policymakers could make important choices when faced with profound trade-offs, and that the sum total of their choices could be described as a 'policy style'. However, the identification of distinctive policy styles can exaggerate the extent to which policymakers control the policy process, and the extent to which we can relate day-to-day decisions and outcomes to a coherent strategy produced by a single elected government. Flexibility can become a veneer for, or acknowledgement of, a lack of control.

Of course, the identification of 'complexity' does not take us very far, without the concepts to help explain what is going on in government. How can we make sense of such a complicated process, to turn it into something that can be analysed in a simple way, to explain the interplay between (a) cross-cutting policy problems and multi-level policy processes, and (b) deliberate and unintended variations in policy outcomes? We examine these processes in three ways, identifying universal, national and case-specific issues.

The first step is to consider why there would be variations in policy outcomes at national and local levels: what are the drivers, and to what extent do they reflect an intentional decision to produce heterogeneous outcomes? We describe 'universal' causes which relate to the interplay between factors such as: the limited extent to which national policymakers pay attention to issues; the potential for ambiguity, or for different policymakers to understand and respond to policy problems in different ways; the silos within government which may produce fragmented policymaking; the extent to which local policymakers have the discretion to go their own way; and 'complex government' in which there is a degree of unpredictability when so many actors are involved, at multiple levels of government, and policies are difficult to control. These factors may be offset by government measures to coordinate policy outcomes - including 'corporate' centres within national and local governments, regulations, performance management, targets and accountability procedures - and by professional norms or policy learning and transfer between governing bodies.

The second step is to consider how specific governments coordinate national policy strategies and balance the trade-offs between national policy and local flexibility. In this case, we examine the 'Scottish approach' as a reputation for distinctive, consultative and flexible, national policymaking. 
The third step is to consider how these processes play out in particular cases. We explore two broad policy fields: 'prevention policy', when governments attempt to intervene early in people's lives to reduce their demand for acute public services; and 'transition policy', when governments address the transition of users from one public service to another. We choose these areas to highlight the ways in which broad policy aims exacerbate 'universal' problems - they cut across departmental functions, require a high degree of coordination by many public bodies at national and local levels, and seem difficult to define and manage - even when governments generate good public sector relationships and a widespread commitment to the policy agenda. We also compare issues with relatively high (prevention) and low (transition) government attention. Our argument is primarily conceptual but, to give greater depth to the relatively abstract case of transition, we outline the case study of transition from child to adult cerebral palsy services.

\section{What drives fragmentation (and coherence) in policymaking?}

\section{'Universal' causes}

When we describe the drivers for differences in policy outcomes as 'universal', we mean that similar processes are identifiable in a large number of political systems and conceptualised in similar ways (Cairney, 2012a, 92):

\section{Attention}

Policymakers can only pay attention to a tiny proportion of the issues for which they are responsible. There is always potential for their attention to lurch from one policy problem to another (Baumgartner and Jones, 1993,31). If issues receive high national level policymaker attention, for a period long enough to define the problem well, they may put in place measures to produce a national policy solution. If low, policy may be underdeveloped and/or left to the discretion of subunits within government departments, public bodies and/or local actors.

\section{Silos}

Policy 'silos' in central government result from the need to break a complex policymaking process down into many more manageable issues involving a smaller number of participants. The government breaks policymaking down into a series of departments, headed by ministers, with their own ways to gather information and produce policy. Ministers delegate most issues to civil servants, who rely on specialist organisations for information and advice. The effect can be fragmentation as a large number of 'policy communities' process policy in different ways often with little interaction between each other (Jordan and Cairney, 2013, 237). These arrangements may be difficult to change. Policymakers 'inherit' laws, rules, institutions and programmes when they enter office (Rose, 1990), and may only have the willingness or ability to challenge a small part. 


\section{Ambiguity}

A key distinction can be made between uncertainty, in which there is imprecision or a lack of information, and ambiguity, in which interpretations of problems can change when people think differently about them (Zahariadis, 2007, 66). Policymakers can understand a problem, and its solution, in very different ways even when faced with the same information. Each government department could have its own idea of the policy problem and its solution. Local policymakers could interpret issues in different ways than national.

\section{Complexity}

'Complexity theory' identifies specific properties and behaviours within complex policymaking systems - including the idea of 'emergence', in which policy outcomes result from the interaction between many actors, based on local rules and practices, often in the absence of central control (Cairney, 2012b). The policy process contains many actors, including a wide range of public bodies, interpreting a convoluted statute book, following different rules and facing different pressures. Fragmentation and local variation may be routine even if there is some degree of central management.

To some extent, these problems can be offset or addressed by:

\section{Professional norms}

One policy 'image' may dominate for long periods, such as when policy revolves around a medical definition of problems, or when public sector professions produce common approaches and standards.

\section{Accountability and central direction}

Government regulations, performance management and other measures could foster meaningful institutional accountability. Or, accountability procedures could be fragmented and difficult to manage, with some bodies accountable to Parliament and the public via government, and others influenced largely by measures designed to promote accountability via local public bodies and service users.

\section{Policy learning}

A national government could encourage, and act as a hub for policy learning and transfer between local areas, many of which may seek guidance on how to operate. However, this process is not straightforward, and there may be central-local tensions associated with the fine line between encouraging and obliging uniformity.

\section{The 'Scottish approach'}

Since 1999, many academic studies have explored the general idea of a 'Scottish policy style', which refers to the ways in which the Scottish Government makes policy following consultation and negotiation with pressure participants such as interest groups, local government organisations and unions (Keating, 2010; Cairney, 2009a; 
2011b; 2013; Cairney and McGarvey, 2013). The Scottish Government may also pursue a distinctive 'governance' style; a relative ability or willingness to devolve the delivery of policy to other organisations in a meaningful way (Cairney, 2009b).

More recently, the Scottish Government has begun to articulate a specific vision of its approach. This process began in early 2007, at the end of the Labour-Liberal Democrat era of 1999-2007, when former Permanent Secretary, Sir John Elvidge, (2013, 31-3), describing the 'Scottish model of government' and the potential to exploit its compact size and close links to public sector bodies, proposed to abolish policy-area specific departments and to give 'organisation wide responsibilities' to civil servants who were previously responsible for discrete areas.

It took off, however, under the SNP-led Scottish Government, elected in May 2007, which introduced a government-wide policy framework, the National Performance Framework (NPF), based on a single 'ten year vision' and a shift towards measuring success in terms of often long-term outcomes (Scottish Government, 2007; 2014a). The NPF has a stated 'core purpose - to create a more successful country, with opportunities for all of Scotland to flourish, through increasing sustainable economic growth'. It seeks to turn this broad purpose into specific policies and measures of success in two main ways. First, it articulates in more depth its national approach via a 'purpose framework' - linked to targets gauging its economic growth, productivity, labour market participation, population, income inequality, regional inequality and (emissions based) sustainability - and five 'strategic objectives':

1. Wealthier and Fairer - Enabling businesses and people to increase their wealth and more people to share fairly in that wealth.

2. Healthier - Helping people to sustain and improve their health, especially in disadvantaged communities, ensuring better, local and faster access to healthcare.

3. Safer and Stronger - Helping communities to flourish, becoming stronger, safer places to live, offering improved opportunities and a better quality of life.

4. Smarter-Expanding opportunities to succeed from nurture through to lifelong learning ensuring higher and more widely shared achievements.

5. Greener - Improving Scotland's natural and built environment and the sustainable use and enjoyment of it.

In turn, these objectives are mapped onto 16 'National Outcomes' and 50 'National Indicators'. It then works in partnership with the public sector to align organisational objectives with the NPF. In particular, local authorities now produce 'Single Outcomes Agreements' (SOAs), in line with the NPF's overall vision and strategic objectives, but with local government discretion to determine the balance between a range of priorities and how they will meet these objectives.

The spirit of the Scottish Government's Concordat with the Convention of Scottish Local authorities (COSLA) suggests that the former will not seek to micromanage local authorities or use external scrutiny and funding to produce compliance with short term targets (Cairney, 2011a, 130; although subnational actors may see this central-local relationship differently). ${ }^{2}$ Instead, the Scottish Government encourages local authorities to cooperate with a range of other bodies in the public sector, including health, enterprise, police, fire and transport, via established 'Community Planning Partnerships' (CPPs), which encourage 'community engagement' and engagement with the third and private sectors, to produce a 'shared strategic vision for an area and a statement 


\section{The 'Scottish approach' to policy and policymaking}

of common purpose' and meaningful long-term outcomes (Cairney and McGarvey, 2013, 139-40). This devolution of power and resources to service providers, and communities at a local level, to deliver national policy priorities, are characteristic of 'localism' (Stoker, 2004b). The NPF allows for considerable discretion for bodies set their own priorities (Keating, 2010, 123-4; Matthews, 2014).

Since 2013, the Scottish Government has sought to further articulate the meaning of 'Scottish approach', in part to further encourage its use, and measure its impact, within the Scottish Government. This now involves giving 'additional priority to:

- Service performance and improvement underpinned by data, evidence and the application of improvement methodologies

- Building on the strengths and assets of individuals and communities, rather than only focusing on perceived deficits

- Services which are shaped and co-produced by both service providers and the citizens and communities who receive and engage with those services.' (Scottish Government and ESRC, 2013, 4)

This development takes place within the context of a changing political environment, in which governments are facing the need to deliver public services on reduced budgets and, as discussed below, the Scottish Government has committed itself to reform public service delivery to help reduce inequalities in areas such as health and education outcomes.

Overall, the 'Scottish approach': began in 1999 as a broad idea about how to govern by consensus in an era of 'new politics'; developed from 2007 as a way to pursue a 'single vision', cross-cutting government aims, and an outcomes-based measure of success, developed in cooperation with the public sector; and became, from 2013, a way to articulate, and measure the impact of, key governing principles ('assets-based', 'co-production', 'improvement methodology') and address specific issues such as inequality. In other words, when articulated by the Scottish Government, 'Scottish approach' describes, increasingly, a large number and mix of specific reforms, aims and principles - and is distinct from the more general academic notion of 'policy style'.

\section{Remember the wider context and don't exaggerate the Scottish style}

It is tempting to relate Scotland's broad policy style to a sense of culture: the Scottish Government appears more willing than the UK to trust local authorities and use more traditional forms of service delivery, which may produce a distinctive approach to governance (Cairney, 2009b, 360; although, see Note 2). Much of the governance literature, which focuses on the UK, highlights the fragmentation of service delivery, particularly from the 1980 s, linked to a history of bypassing local authorities - to rely more on quangos, often designed specifically to deliver policy in new ways - and encouraging a wide range of third and private sector bodies to deliver services (Rhodes, 1997; Gray, 2000, 283-4; Greenwood et al, 2001, 153-7; Stoker, 2004a, 32). This was followed by attempts to coordinate policymaking through policy networks, followed by a more top-down attempt to 'regain control over policy outcomes' (Richards and Smith, 2004, 343) - a process associated with strict target setting (Hood, 2007). Only recently have we seen a resurgence of the idea of 'localism' as a policy aim (Local 
Government Association, 2013) and initiatives such as the devolution of significant powers to a Greater Manchester Combined Authority.

Yet, the Scottish style may relate specifically to the size or scale of Scottish Government, which allows relatively close personal relationships to develop between key actors, and closer links to develop across departmental 'silos'. The low capacity of the Scottish Government also prompts civil servants to rely more, for information, advice and support, on experts outside of government and the actors who will become responsible for policy implementation. In contrast, UK government policies travel further distances and they make greater attempts to control far more organisations, with less scope for personal relationships.

Further, such comparisons downplay the wider context of Scottish policymaking in five main ways. First, the Scottish approach developed during an increase in public expenditure from 1999 until the mid-to-late 2000s, with comparatively few 'hard choices' and major policy disagreements. Second, the Scottish Government has not been immune from long-term international trends such as 'new public management'. It oversees a large and complicated public sector landscape, consisting of government agencies, quangos, local authorities, health boards and service delivery organisations in the third and private sector. As in the UK, it has an extensive regulatory and audit function to address this proliferation of bodies (Cairney and McGarvey, 2013, 149).

Third, a focus on 'Scottish' styles may downplay the multi-level nature of policymaking, in which the Scottish level plays one part. The UK government still largely determines the Scottish Government's budget, and key policies - including economic, social security and employment - have a marked effect on devolved policies. Intergovernmental issues arise, for example, when devolved public services overlap with reserved social security and taxation arrangements. Some of these overlaps will become more significant following further devolution, since the Smith Commission on further Scottish devolution, to be implemented after the 2015 UK General Election, recommends shared powers in areas such as taxation, energy and social security (McEwen and Petersohn, 2015).The EU dimension also overlaps with devolved responsibilities, directly in areas such as environmental policy, agriculture and fisheries, and indirectly in areas such as employment.

Fourth, departmentalism and 'policy communities' are pervasive because the same logic of policymaking exists across a wide range of countries. Silos develop because ministers and civil servants have their own responsibilities and only a limited time in which to engage with actors outside of their departments. There are inescapable trade-offs between departmental specialisation and cross-departmental policymaking (Jordan and Halpin, 2006). Actors with limited resources focus on particular issues and hubs of activity, and only have a limited time in which to understand and engage with others. There will also be winners and losers from regular consultation, which can be "condemned as ruled by "special interests" or praised as "stakeholder empowerment" (Keating, 2010, 3).

Fifth, since devolution, there is little evidence that Scottish policymaking differences have produced major differences in policy outcomes. For example, the more critical social policy literature, some of which challenges the idea of a distinctive Scottish approach (Mooney and Poole, 2004; Law and Mooney, 2006), suggests that inequalities in areas such as education, health and crime remain stubbornly high (Mooney and Scott, 2012; Scott and Mooney, 2009, 380-1). 


\section{The 'Scottish approach' to policy and policymaking}

Overall, the Scottish approach may be distinctive, but we should not assume or overestimate its effect. Compared to the UK, we can identify generally greater potential for senior policymakers to form personal networks with pressure participants such as interest groups and public bodies, which could help address:

- $\quad$ silos, if the Scottish Government sets a national framework with cross-cutting aims, and gives ministers responsibilities which span departments;

- ambiguity, if participants interact regularly to define and address policy problems; - discretion, if national and local actors interact regularly - and learn from each other - to produce common policy aims.

On the other hand, the Scottish approach may refer to the pursuit of a more bottomup, or less top-down, approach to policy implementation; the encouragement of 'community' led policies. It implies a decision to encourage discretion, the production of a meaningful degree of local policymaking, and perhaps the acceptance that some policies may 'emerge' in the absence of central direction (Sanderson, 2011). Longterm policymaking outcomes are also uncertain. For example, local authorities and their partners could develop a more 'corporate' approach to problems, producing agreements that cut across traditional boundaries and provide for jointly resourced responses between bodies in areas such as health, education and policing. Or, departments could rely on more established relationships between professionals and specialists at local and national levels.

The Scottish Government shares the same problems as other governments. Accountability measures become rather convoluted as, for example, highly-regulated aims or high stakes performance measures in individual areas ('P45 targets') run in parallel with cross-cutting longer-term aims on which everyone agrees but does not prioritise. Regular discussion does not remove ambiguity or produce governmentwide agreement on how to understand and solve problems. Actors may have the ability to break down some aspects of some silos, but not to completely change the ways in which people specialise and group together. Actors have the ability to import policy solutions, but have limited resources to understand why and how they should do so.

\section{Case study: prevention policy}

The Scottish Government (2011) made a commitment to 'achieving a decisive shift to prevention' following its 'post-Christie' agenda to reform public services, address inequalities and reduce demand for reactive or acute level services.

'Prevention' is a term in good currency, internationally, partly because it is vague enough to generate widespread support. The general aim is for governments to address a wide range of longstanding problems - including crime and anti-social behaviour, ill health and unhealthy behaviour, low educational attainment, and unemployment - at source, before they become too severe or expensive. At this abstract level, prevention can appear to generate widespread and long-term consensus, to bring together: groups on the 'left', seeking to reduce poverty and inequality, and the 'right', seeking to reduce economic inactivity and the costs of services (Billis, 1981, 367); or, policymakers, scientists, professionals and interest groups with a general commitment to predicting and solving policy problems (Freeman, 1999). However, it is more of a normative policy ideal, a vague but important 'communicative practice' (Fischer and Gottweis, 
2012), than a concrete policy. Only detailed policies will determine who gets to participate in designing prevention, what values and solutions will be entertained in the policy debate, and who stands to gain or lose.

A 'decisive shift to prevention' is only meaningful if attached to a more detailed vision - as provided, to some extent, by four 'Christie Commission' principles:

- 'Reforms must aim to empower individuals and communities receiving public services by involving them in the design and delivery of the services they use.

- Public service providers must be required to work much more closely in partnership, to integrate service provision and thus improve the outcomes they achieve.

- We must prioritise expenditure on public services which prevent negative outcomes from arising.

- And our whole system of public services - public, third and private sectors - must become more efficient by reducing duplication and sharing services wherever possible.' (Commission of the Future Delivery of Public Services, 2011, vi)

The Commission examined how to reduce inequalities, improve 'social and economic wellbeing' and spend less money, in the context of: (a) over 10 years of high postdevolution spending producing minimal or adverse effects on inequalities; (b) the likelihood of reduced budgets for over 10 years; and, (c) rising demand for public services, resulting from a combination of demographic change, such as an ageing population, and 'failure demand', or the high cost of a public service when it treats acute problems (2011, viii, 7, 16, 75). To do so requires the Scottish Government to address its unintended contribution to a 'cycle of deprivation and low aspiration' by: redirecting spending towards preventative policies in a major way (2011, viii; 6-7); changing its relationship with delivery bodies; addressing a lack of joint working in the public sector, caused partly by separate budgets and accountability; and, engaging 'communities' in the design and delivery of public services, rather than treating them as 'passive recipients of services' $(2011,27)$. It also identifies the types of projects on which a prevention agenda can draw, including those which:

- 'personalise' service delivery by, for example, encouraging disabled service users to negotiate the details of their care $(2011,28-9)$ or encourage 'recovery' from addiction $(2011,31)$

- train 'kinship' carers, to reduce the need for cared-for people to use expensive public services $(2011,31)$

- foster social networks to address the mental health effects of isolation $(2011,32)$

- involve partnerships with third sector bodies $(2011,33)$

- involve 'bottom-up' service delivery through organisations such as community development trusts $(2011,34)$

- focus specifically on inequalities in areas such as training and work $(2011,57)$

- focus specifically on 'the needs of deprived areas and populations' $(2011,59)$.

The Scottish Government $(2011,6)$ response was positive, signalling 'a decisive shift towards prevention' and 'a holistic approach to addressing inequalities'. It sought to turn this agenda into specific aims by: 


\section{The 'Scottish approach' to policy and policymaking}

- $\quad$ listing its existing prevention-led projects, including a focus on early years (and poverty) investment, class sizes and curriculum reform, employment training, tobacco, drug and alcohol control,'inequalities-targeted health checks', alternatives to short-term custodial sentences, affordable housing, energy assistance and community-based carbon emissions reduction projects (although note the potential to merely rebrand existing activities as preventive).

- announcing three new funds, representing $6500 \mathrm{~m}$ 'investment in preventative spending' from Scottish Government and public body funds - a 'Change Fund for older people's services' (primarily NHS budget), an 'Early Years and Early Intervention Change Fund' (NHS and local authorities) and a 'Reducing Reoffending Change Fund' (with high third sector involvement) - and a 'Scottish Futures Fund' bringing together spending on youth sport, broadband, Sure Start, fuel poverty and public transport encouragement.

- $\quad$ outlining its specific priorities up to 2016, to expand nursery education and reduce class sizes, roll out Getting it Right for Every Child (GIRFEC), increase funding $(£ 30 \mathrm{~m})$ on early cancer detection, introduce a minimum unit price on alcohol and further tobacco control, regenerate 'disadvantaged communities' and support community-based renewable energy schemes. (2011, 6-9)

\section{Prevention: the ultimate multi-level, cross-cutting issue?}

Prevention policy sums up the problem of 'complex government'. Attention is high and there is widespread commitment throughout the public sector to a prevention agenda (interviews, Scottish Government, 2013; Local Government Improvement Service, 2014).Yet, 'decisive shift to prevention' is plagued by ambiguity. It can: mean anything from a whole population inoculation to addressing specific outcomes on specific groups; describe short-term and major, or long-term and incremental, change; and, involve a priority of reducing inequalities or costs (but note that many prevention initiatives do neither). There is great potential for silos to change rather than be broken down - such as in community policing rather than policing, or early years policies bringing together health and education but not planning, transport and environment. A commitment to community and service user-led policy provides great scope for local rules in which individuals and public bodies interact. There is a complex system composed of multi-level, departmental and central-local issues - all multiplied by the large number of cross-cutting policy fields addressed by the Scottish Government.

\section{The Scottish Government response in practice: pragmatic flexibility?}

The Scottish Government approach has been to set out a broad strategy and encourage local bodies, through vehicles such as CPPs, to meet common aims. This process is in its infancy. Guidance issued by COSLA and the Scottish Government (2012; Scottish Government, 2014b) was produced too late to inform local plans in a meaningful way. Consequently, the SOAs as a whole demonstrate a very broad commitment to the NPF and prevention, with differences driven by each area's response to its geographical and socio-economic conditions, potential to give meaning to prevention in different ways, and a tendency to re-describe existing projects (Cairney and St Denny, 2014). The process of producing more meaningful joint aims, and a common language around outcomes continues, but in the context of a more pressing political process producing 
Scottish Government commitments in non-preventative areas, including to maintain targets on police numbers, hospital waiting times and teacher:pupil ratios. Future measures of progress include: the incorporation of prevention into core budgets, the decision by multiple public bodies to pool staffing and other major resources, and the extent to which one silo is replaced by another. A broad commitment to prevention as an idea still rubs against a local and national imperative to play down these aims in manifestos until parties can find the right language to sell them.

\section{Case study: transition}

We define transition as the process of transfer from a service for young people, such as from: paediatric health services or social care, one level of education to another, education to training, or young offender institutions to participation in society. In some cases, the transition is from child to adult services. In others, it is from receiving a service as a child to no equivalent service (Cashmore and Paxman, 2006; Dixon and Stein, 2002; Biggart and Walter, 2006; Wade, 2008; Jackson and Cameron, 2012). Consequently, there are different kinds of issues addressed by different parts of government and, in areas including social security and public services, up to three levels of government.

Transition receives less government attention: there is no equivalent to the 'decisive shift to prevention'. Rather, 'transition policy' is a term we use to describe a range of relevant practices and strategies, rather than a single government document. Since it is relatively abstract and difficult to pin down, we add depth to the discussion by outlining a concrete case study of transition from child to adult cerebral palsy services.

\section{Transition from child to adult services: the example of cerebral palsy}

Learning or physical disabilities present particular challenges: young people may find it more difficult to maintain social relationships and to ensure that appropriate health care is maintained. Transition may also be seen as a lifelong process. Cerebral palsy $(\mathrm{CP})$ is a complex condition and its treatment is cross-cutting - a person may require health and social care as well as other care and financial support, depending on the severity of the condition, which varies markedly across the population (Levitt, 2010, 1).Yet, it is not an area of policy in its own right. While, in some NHS institutions, there is a specific CP care pathway, it is usually addressed under more general strategies around transition. For example, a young person may be covered by the physical or learning disabilities protocol in their local area.

The main issue regards the possibility that people move from a well-coordinated and funded service to a markedly reduced service. Care for neonates and young children in paediatric services is coordinated well, and the various disciplines cooperate to provide this service (for example, physicians, physiotherapists, occupational therapists, education specialists and social workers). Conversely, care within the adult environment is less well coordinated. This leads to often-fragmented provision.

\section{Attention}

Low policymaker attention, coupled with a high level of discretion, creates a space for policies to develop with minimal national direction. CP was historically a niche 


\section{The 'Scottish approach' to policy and policymaking}

concern of medical and health professionals, particularly in relation to adults, partly because: there is no cure; the life expectancy and numbers of adults with CP has, in the past been unclear; and there is a belief among many physiotherapists that their effort can be of greater value in treating infants and young children (Bottos et al, 2001, 516; Redmond and Parrish, 2008). Evidence since the 1990s suggests that the survival rate, to age 30, is at least 85 per cent (Ali et al, 2009, 44-5) and that many people with CP can participate strongly in society when 'assisted by legislation, advances in technology and changing attitudes in their society' (Levitt, 2010,1).Yet, the survival rates for other lifelong and long-term conditions are also increasing and there is greater competition for limited resources, including policymaker attention. This problem may have been exacerbated by a general, albeit welcome, shift from institutionalised to community care, which shifts much care from more established, and often more vocal, professions, to part-time or unpaid carers (Harris and Roulstone, 2011).

Discretion around transition can be a positive development, producing the opportunity to personalise services around individuals. Yet, while public bodies have high levels of discretion for child and adult care, they have more regular reference points for children - such as the (now amended) Additional Support for Learning (Scotland) Act 2004 requiring a local authority to produce a coordinated support plan for young people with additional support needs (Scottish Government, 2010), and the GIRFEC framework. Attention to adult care and transition is more likely to occur in individual case reviews when problems have arisen. In some cases, individuals may remain under the care of children's services because they or their family are not yet ready for the transfer to happen. A very gradual process may occur, in which case children's services work alongside their adult counterpart to provide a service until the young person is ready to transition fully.

\section{Silos}

CP transition involves coordination between a large number of departments and bodies, including education, social work and healthcare. Problems develop when, for example, a document produced by one local department is implemented by another, with different skills and ideas. There are two kinds of solution: more cooperation between separate bodies, or a distinct transition team. In the former, good communication relies heavily on personal relationships and a manageable population or service size - both of which are absent in many areas. These issues are more pronounced in adult care, with service users more responsible for accessing a range of separate services. Transition teams may solve some of these problems but also, ironically, create new silos when over-focused on the issue of transition at the expense of other aspects of each service. Teams may take on responsibility for transition, and other professionals may become less engaged with each other.

\section{Ambiguity}

There is broad agreement on the meaning of transition, as a period of change in a young person's life prompted by a move to adult services from child orientated services. Beyond this abstract agreement, there is confusion about the reference of transition to, for example, a whole of life approach, or a much more finite event, and these different understandings are held in different services or areas. 


\section{Complexity}

There are multiple layers of complexity in CP: individual people with very different 'complex needs', which require individual attention from a wide range of bodies, interact with a complex network of policies and people across multiple Scottish Government departments and levels of government. For example, in one local authority, over 40 different individuals from organisations outside the social work profession were represented at a local stakeholder event. The UK government also maintains control over certain areas of welfare, work and employability policy (although some may be devolved in 2015).

These factors may be offset by government measures designed to coordinate policy outcomes, such as the care inspection process, but we find a general perception among interviewees that the government does not have a clear overview of the transition process. There is no clear pattern of learning via professional bodies, and policy transfer across health and local authorities is patchy, largely because local areas tend not to know much about practice in other regions.

\section{Conclusion}

The Scottish Government has nurtured a reputation for doing policy differently - the 'Scottish approach' - and academic studies have tended to use the UK as a comparator, to identify a 'Scottish policy style'. Politically, such phrases may be used to laud Scottish politics and policymaking, compared to the worst excesses of 'neoliberal' UK government and governance.Yet, the danger is that this comparatively good reputation distracts us from detailed analysis of the extent to which the Scottish Government faces the same problems as any other, and addresses them often in similar ways. Some policy problems are territorial, but many are universal.

First, there is an inescapable trade-off between a desire to harmonise national policies and to encourage local discretion. Policymakers and participants understand this problem in different ways; some bemoan the 'fragmentation' of public services and the potential for a 'postcode lottery'; others identify more positive notions of flexible government, the potential for innovation, and the value of 'community-led' policies or individualised services.

Second, policymakers have a limited amount of control over this trade-off. They do not choose a level of fragmentation. Instead, they face the same: ability to pay attention to only a small proportion of public service activity; tendency for problems to be processed in government silos; potential for policymakers, in different departments or levels of government, to understand and address the policy problem in very different ways; and, 'complexity', which suggests that policy outcomes often 'emerge' from local action in the absence of central control. These problems can only be addressed in a limited way by strategies based on the maintenance of professional norms, use of accountability and performance measures, and encouragement of learning between public bodies.

The 'Scottish approach' could help address problems associated with silos, ambiguity and discretion, if policy is 'co-produced' and 'owned' by national and local bodies. On the other hand, it implies a decision to encourage discretion, a meaningful degree of local policymaking, and the acceptance that some policies may 'emerge' in the absence of central direction. It is difficult to tell, from its 'approach' alone, what 


\section{The 'Scottish approach' to policy and policymaking}

policy outcomes will be, and how much they can be traced back to the policies and policymaking strategies of specific governments.

Some issues seem more likely to exacerbate these 'universal' problems more than others. We demonstrate this point by outlining two policy areas, on prevention and transition, which cross-cut government departments and multiple levels, and seem particularly difficult to define and manage. In both cases, the problem is not one of generating consensus or 'ownership' (a potential advantage of the Scottish approach). In fact, there is commitment to both issues, and to achieve a 'decisive shift to prevention' in particular. Rather, the problem is often one of ambiguity - people are not quite sure what prevention or transition mean in practice, when applied to different kinds of policy problem - or fragmentation, when a range of public bodies seek, partly in vain, to work together to produce more specific aims and objectives. This is taking place during a period of financial retrenchment, where a broad appeal to valence terms like prevention may mask profound changes that produce clear winners and losers.

These 'universal' points are important when we consider Scottish policymaking in the context of the current debate on constitutional change: a further shift of policymaking responsibility from the UK to Scotland may reduce one aspect of complex government, but many would still remain. In cases such as prevention, further devolution could have an impact on budget priorities, and the link between the social security system (currently reserved to the UK) and public services. It would not, however, solve the problem of how to define and address cross-cutting and ambiguous problems. These issues tend to be ignored during debates, at least when the Scottish Government is seen to have a much better reputation for policymaking than its UK counterpart.

\section{Notes}

${ }^{1}$ We use 'national' to refer to Scottish national. Our comparison is Scottish national/ local government and UK national/local government.

${ }^{2}$ McAteer (2014) argues that 'Scotland continues to operate a largely centralised, top-down and de-localised local government system'. Compare statements by COSLA Presidents: in 2007, Watters talked about local government now having greater responsibility and 'the freedom and flexibility to respond effectively to local priorities' (Cairney, 2011a, 130); in 2014, O’Neill (2014) argued that, 'Over the decades, we've seen a culture in which more and more services and decisions been taken away from local communities and put into the hands of distant bureaucracies.'The Scottish Government provides above 80 per cent of local government funding (Cairney and McGarvey, 2013, 138).

\section{Acknowledgement}

This work was supported by the Economic and Social Research Council (grant number ES/L003325/1)

\section{References}

Ali, R, Ahmed, S, Qadir, M, 2009, Cerebral palsy in adolescents, Pakistan Journal of Neurological Sciences 4, 1, 44-5

Baumgartner, F, Jones, B, 1993, Agendas and instability in American politics, Chicago, IL: Chicago University Press

Biggart, A, Walther, A, 2006, Coping with yo-yo transitions, in C Leccardi, E Ruspini (eds) A new youth?, pp. 41-62, Farmham and Burlington,VT: Ashgate 
Billis, D, 1981, At risk of prevention, Journal of Social Policy 10, 3, 367-79

Bottos, M, Feliciangeli,A, Scuito, L, Gericke, C,Vianello, A, 2001, Functional status of adults with cerebral palsy and implications for treatment of children, Developmental Medicine and Child Neurology 43, 516-28

Cairney, P, 2008, Has devolution changed the British policy style?, British Politics 3, $3,350-72$

Cairney, P, 2009a, The 'British policy style' and mental health, Journal of Social Policy $38,4,1-18$

Cairney, P, 2009b, Implementation and the governance problem, Public Policy and Administration 24, 4, 355-77

Cairney, P, 2011a, The Scottish political system since devolution, Exeter: Imprint Academic

Cairney, P, 2011b, The new British policy style: From a British to a Scottish political tradition, Political Studies Review 9, 2, 208-20

Cairney, P, 2012a, Understanding public policy, Basingstoke: Palgrave

Cairney, P, 2012b, Complexity theory in political science and public policy, Political Studies Review 10, 3, 346-58

Cairney, P, 2013, Territorial policy communities and the Scottish policy style: The case of compulsory education, Scottish Affairs 82, Winter, 10-34

Cairney, P, 2015, What is complex government?', Public Money and Management 35, $1,3-6$

Cairney, P, Geyer, R, 2015, Introduction, in R Geyer, P Cairney (eds) Handbook of complexity and public policy, Cheltenham: Edward Elgar

Cairney, P, McGarvey, N, 2013, Scottish politics, 2nd edn, Basingstoke: Palgrave

Cairney, P, St Denny, E, 2014, A framework to decide 'what works' in prevention policy, paper to Scottish Government, February, http://www.futureukandscotland. ac.uk/sites/default/files/papers/Cairney\%20St\%20Denny\%20Prevention\%20 Paper\%2021.2.14.pdf

Cashmore, J, Paxman, M, 2006, Predicting after-care outcomes: The importance of 'felt' security, Child and Family Social Work 11, 3, 232-41

Commission of the Future Delivery of Public Services, 2011, Report, Edinburgh: Scottish Government, www.scotland.gov.uk/Resource/Doc/352649/0118638.pdf

COSLA and the Scottish Government, 2012, Community planning review: Statement of ambition, www.scotland.gov.uk/Topics/Government/local-government/CP/soa

Dixon, J, Stein, M, 2002, Still a bairn? Throughcare and aftercare services in Scotland: Final report to the Scottish executive, York: University of York for the Scottish Executive

Elvidge,J, 2013, Northern exposure: Lessons from the first twelve years of devolved government in Scotland, London: Institute for Government, www.instituteforgovernment.org. $\mathrm{uk} /$ sites/default/files/publications/Northern\%20Exposure.pdf

Fischer, F, Gottweis, H, 2012, Introduction: The argumentative turn revisited, in F Fischer, H Gottweis (eds) The argumentative turn revisited: Policy as communicative practice, pp 1-27, Durham, NC: Duke University Press

Freeman, R, 1999, Recursive politics: Prevention, modernity and social systems, Children and Society 13, 232-41

Gray, C, 2000,A 'hollow state’?, in R Pyper, L Robins (eds) United Kingdom governance, Basingstoke: Palgrave Macmillan

Greenwood, J, Pyper, R, Wilson, D, 2001, New public administration in Britain, London: Routledge 


\section{The 'Scottish approach' to policy and policymaking}

Harris, J, Roulstone, A, 2011, Disability policy and professional practice, London: Sage Publications

Hood, C, 2007, Public service management by numbers, Public Money and Management 27, 2, 95-102

Jackson, S, Cameron, C, 2012, Leaving care: Looking ahead and aiming higher, Children and Youth Services Review 34, 6, 1107-14

Jordan, G, Cairney, P, 2013, What is the 'dominant model of British policymaking'?, British Politics 8, 3, 233-59

Jordan, G, Halpin, D, 2006, The political costs of policy coherence, Journal of Public Policy 26, 1, 21

Keating, M, 2005, The Government of Scotland, 2010, 2nd edn, Edinburgh: Edinburgh University Press

Law, A, Mooney, G, 2006, 'We've never had it so good': The problem of the working class in devolved Scotland, Critical Social Policy 26, 3, 523-42

Levitt, S, 2010, Treatment of cerebral palsy and motor delay, Oxford:Wiley-Blackwell

Local Government Association, 2013, Localism Act, www.local.gov.uk/localism-act

McAteer, M, 2014,What future for local government in a post referendum Scotland?, paper to Political Quarterly workshop, Edinburgh, October

McEwen, N, Petersohn, B, 2015, Between autonomy and interdependence, Political Quarterly, http://onlinelibrary.wiley.com/doi/10.1111/1467-923X.12162/abstract

Matthews, P, 2014, Being strategic in partnership, Local Government Studies, www. tandfonline.com/doi/abs/10.1080/03003930.2013.859141\#.Uv433cZFCUk

Mooney, G, Poole, L, 2004, A land of milk and honey? Social policy in Scotland after devolution, Critical Social Policy 24, 4,: 458-83

Mooney, G, Scott, G (eds), 2012, Social justice and social policy in Scotland, Bristol: Policy Press

O'Neill, D, 2014, Time to reverse 50 years of centralization, Edinburgh: Commission on Strengthening Local Democracy, www.localdemocracy.info/2014/04/24/timeto-reverse-50-years-of-centralisation/

Redmond, R, Parrish, M, 2008,Variables influencing physiotherapy adherence among young adults with cerebral palsy, Qualatitive Health Research 18, 11, 1501-10

Rhodes, AW, 1997, Understanding governance, Milton Keynes: Open University Press

Richards, D, Smith, M, 2004, The 'Hybrid State', in S Ludlam, M Smith (eds) Governing as New Labour, London: Palgrave

Rose, R, 1990, Inheritance Before Choice in Public Policy, Journal of Theoretical Politics 2, 3, 263-91

Sanderson, I, 2011, Evidence-based policy or policy-based evidence? Reflections on Scottish experience, Evidence and Policy 7, 1, 59-76

Scott, G, Mooney, G, 2009, Poverty and social justice in the devolved Scotland: Neoliberalism meets social democracy?, Social Policy and Society 8, 3, 379-89

Scottish Government, 2007, Performance, 2014a, 2nd edn, Edinburgh: Scottish Government, www.scotland.gov.uk/About/Performance

Scottish Government, 2010, Supporting children's learning code of practice (Revised edition), Edinburgh: Scottish Government, www.scotland.gov.uk/Resource/ Doc/348208/0116022.pdf

Scottish Government, 2011, Renewing Scotland's Public services, Edinburgh: Scottish Government, www.scotland.gov.uk/Publications/2011/09/21104740/0 
Scottish Government, 2012, Single outcome agreements: Guidance to community planning partnerships, Edinburgh: Scottish Government

Scottish Government, 2014b, Final single outcome agreements 2013, Edinburgh: Scottish Government)

Scottish Government and ESRC, 2013, What Works Scotland (WWS), www.esrc. ac.uk/_images/WWS\%20Call\%20spec\%20FINAL\%2006\%20Jan\%202014_tcm829575.pdf

Stoker, G, 2004a, Transforming local governance, Basingstoke: Palgrave Macmillan

Stoker, G, 2004b, New localism, progressive politics and democracy, Political Quarterly $75,1,117-29$

Wade, J, 2008, The ties that bind, British Journal of Social Care 38, 1, 39-54

Wishart, A, 2011, 23 week babies, BBC 2 Scotland, 9 March

Zahariadis, N, 2007, The multiple streams framework, in P Sabatier (ed) Theories of the policy process, Cambridge, MA: Westview 